\title{
Analysing the Local Communities' Perception on the Economic and Environmental Factors of Ecotourism in Tagang System Framework: The Case of Semedang Village, Sarawak, Malaysia
}

Nur Zaimah Ubaidillah, Rossazana Ab-Rahim, Sutera Jul, A.B. Nor Afiza Salbiah Edman and Rosita Hamdan

To Link this Article: http://dx.doi.org/10.6007/IJARBSS/v8-i11/4984

DOI: 10.6007/IJARBSS/v8-i11/4984

Received: 17 Oct 2018, Revised: 13 Nov 2018, Accepted: 16 Nov 2018

Published Online: 14 Dec 2018

In-Text Citation: (Ubaidillah, Ab-Rahim, Jul, Edman, \& Hamdan, 2018)

To Cite this Article: Ubaidillah, N. Z., Ab-Rahim, R., Jul, S., Edman, A. B. N. A. S., \& Hamdan, R. (2018). Analysing the Local Communities' Perception on the Economic and Environmental Factors of Ecotourism in Tagang System Framework-The Case of Semedang Village, Sarawak, Malaysia. International Journal of Academic Research in Business and Social Sciences, 8(11), 1056-1068.

Copyright: (C) 2018 The Author(s)

Published by Human Resource Management Academic Research Society (www.hrmars.com) This article is published under the Creative Commons Attribution (CC BY 4.0) license. Anyone may reproduce, distribute, translate and create derivative works of this article (for both commercial and non-commercial purposes), subject to full attribution to the original publication and authors. The full terms of this license may be seen at: http://creativecommons.org/licences/by/4.0/legalcode

Vol. 8, No. 11, 2018, Pg. 1056 - 1068 


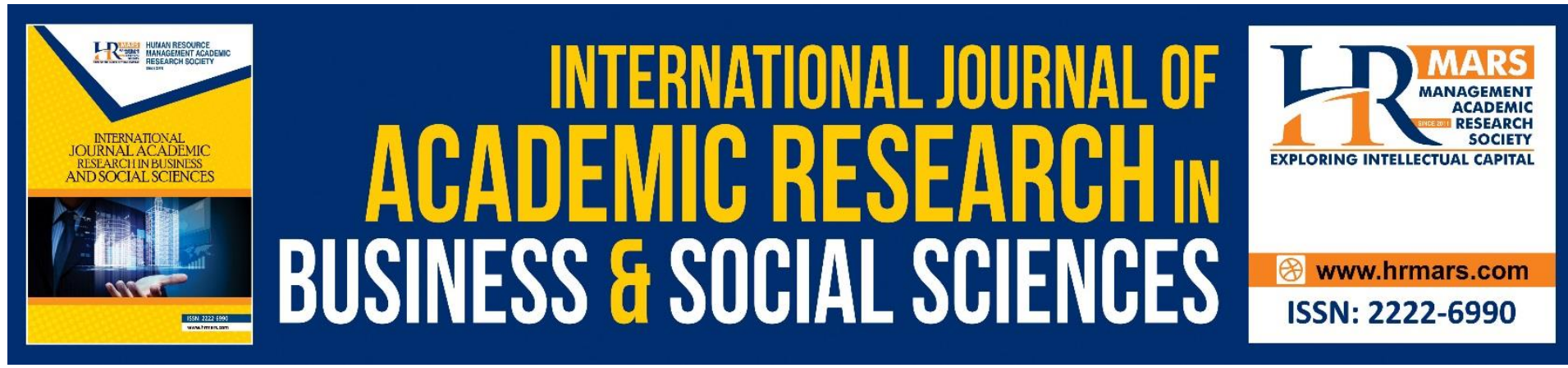

\title{
Analysing the Local Communities' Perception on the Economic and Environmental Factors of Ecotourism in Tagang System Framework-The Case of Semedang Village, Sarawak, Malaysia
}

\author{
Nur Zaimah Ubaidillah ${ }^{1}$, Rossazana Ab-Rahim, Sutera Jul, \\ A.B. Nor Afiza Salbiah Edman and Rosita Hamdan \\ Faculty of Economics and Business, Universiti Malaysia Sarawak, Sarawak, Malaysia.
}

\begin{abstract}
Ecotourism is a natural product that plays a role in enhancing the economy of a country. Tagang system is a new tourism product that contributes to a more efficient environmental management, contributing to economic development, and social development of communities. The objective of this study was to identify the factors that influence the development of Tagang system in ecotourism framework at Semedang village. A total of 63 surveys were collected using random sampling method. Data were analysed using the reliability test and factor analysis. The results showed that there are four contributing factors of Tagang system in the Semedang village which are economic development, conservation of the natural area, awareness of Tagang advantages and biodiversity management.
\end{abstract}

Keywords: Tagang System, Economic Development, Conservation, Biodiversity Management

\section{INTRODUCTION}

Tourism is a growing sector in the states in Malaysia, particularly Sarawak. In Sarawak, tourism is the second most important sector in contributing revenue to the state economy. In this past few decades, there is a trend towards tourism which exclusively focus on nature, natural areas, and centres around conservation (Cooper \& Wanhill, 1996). This situation can be seen through the government's effort for the development which is carried out in the rural areas for tourism purposes. For that particular reason, the Tagang system is introduced as one of the nature based tourism activities in Sarawak. Tagang comes from Iban word which means regulation and conservation of river fish based on communities. In Malaysia, this system only introduced in Sarawak and Sabah (known as Tagal system or bombom) as other states still did not provide apparent or clear information about the essence of the system.

Wong et al. (2009) stated that this system was initially used to preserve the forest by the local community before being adapted to the conservation and management of rivers. This system

${ }^{1}$ Corresponding author. Email: unzaimah@unimas.my 
is biosphere management to maintain the sustainability of natural products from being contaminated (Foo, 2011). Based on this system, the using of natural resources is limited by applying the reserve zone and the limitation of harvesting the river resource. Wong et al. (2009) stated that the system act as a fishing ban based on the agreement of the community within a specified period to overcome the shortage of freshwater resources and prevent pollution of rivers, as well as to generate the community income. Therefore, Tagang system is intended to raise awareness about conservation and community commitment towards enhancing fish production for food, providing a continuous source of income for the villagers, as well as promoting ecotourism.

Since 2006, 52 areas or villages practiced the Tagang system until now in Sarawak. Tagang programs are organized by the Sarawak Forestry Corporation (SFC) in collaboration with the Forest Department of Sarawak (JHS) and the Department of Agriculture. The first Tagang system was introduced in 2006 at Brayong's river, Long Tuyo. A total of 9500 species of fish are released into the river including empurau, tengadak, jelawat, and sayan. The implementation of a Tagang system in the village also creates a sense of responsibility to prevent, control, and reduce the pollution of rivers to preserve the natural environment for future generations. The launch of Tagang system has gradually restored the fishery resources in the river and declined the illegal fishing. The close collaboration between government agencies and the local community is the main factor of Sarawak's project successful.

This system is quite different from other methods because it emphasises the balance of the natural ecosystem. The Tagang system is assumed to be able to attract ecotourism activities because the tourists are very fond of visiting natural areas because they prefer adventurous activities while enjoying nature's beauty. Besides enjoying the natural beauty, tourists also like to see the customs and cultures of the community especially Bidayuh's community which is the majority of people living in Semedang village. Cultural customs and lifestyle of Bidayuh community are different according to their respective places. The uniqueness of food is also a source of tourist attraction. The tourist wants to see, feel and experience the delicious traditional food prepared by the local community.

Therefore, to improve the ecotourism, the local community should be involved in tourism activities such as the Homestay program, become a tourist guide, providing services such as kayaking, rafting, and others. The introduction of Tagang system could be able to generate the residents' income, encourage the community to be independent and not to rely merely on agricultural activities such as planting rice, rubber, cocoa, palm oil, poultry and some other agricultural commodities. Tagang project can improve the local communities' quality of life in line with the government vision to improve the economy in rural areas.

Accordingly, some remote areas have the potential to be introduced as one of the area for tourism activities such as Semedang village. Semedang village is popularised as an ecotourism destination when Tagang system introduced in this village in the year 2008. Tagang system implementation requires research and careful planning so as not to cause the river ecosystem being affected while maintaining the environment. The management that organises systematically will be one of the initiatives to improve the sustainability of biodiversity in the village particularly the sustainability of Semedang river. This study is undertaken to examine 
whether Tagang system serves as one of the attractions of ecotourism activities to maintain, preserve, and protect the environment carefully so that it remains essential for the long-run sustainability.

According to Wearing \& Neil (1999), ecotourism activity is focused on the knowledge and awareness of the importance of nature. Education and outreach are not only required from the organisations involved in tourism activities but also of society itself. Through knowledge and awareness, it can serve as a motivating factor for ecotourism Wearing \& Neil (1999). In the context of Tagang system maintenance for ecotourism, the development activities carried out should emphasize the acceptance of the local community about the existence of the system. If evaluated logically, the involvement of the local community is significant in maintaining their environment so they do not feel deprived and can understand the importance of the implementation of Tagang system in their village. Therefore, this study attempts to identify whether the Tagang system current situation and the involvement of local communities in operation performed as well as the effect of the presence of ecotourism itself to the community in the village.

The study is carried out to identify the factors of Tagang system development in the ecotourism framework of the Semedang village in seeking a better understanding of issues and problems encountered by the local communities.

\section{DATA \& METHODOLOGY}

This study is conducted at Semedang village which is located near Borneo Highland, Kuching, Sarawak. Semedang village is located about $131 \mathrm{~km}$ and takes about 1 hour and 30 minutes' drive from Samarahan area. This village is rich in environmental resources, including forest and river. Semedang River is known as a river that is managed through system management called Tagang in which kayaking activities, fish feeding, and water rafting serve as its famous tourism activities. There are 680 of populations, and a majority of the local communities are Bidayuh who profess Christianity. The main jobs of the local communities are farmers, small and medium businesses, government and private sector employees. However, since the village is recognized as a tourism destination, some of the local communities have a new job in the tourism sector, while, they already have more than one source of income, on a regular basis or part-time.

Ecotourism protects the natural areas, especially the river via the implementation of Tagang system. The application of Tagang system will contribute to the villagers' revenue, conservation of the environment, and the involvement of the local community, and thus give impacts in socioeconomic for community livelihood and environment whether there have or not protection and management to sustain the biodiversity. Each of these contributions and impacts is basic to the overall success of ecotourism. 


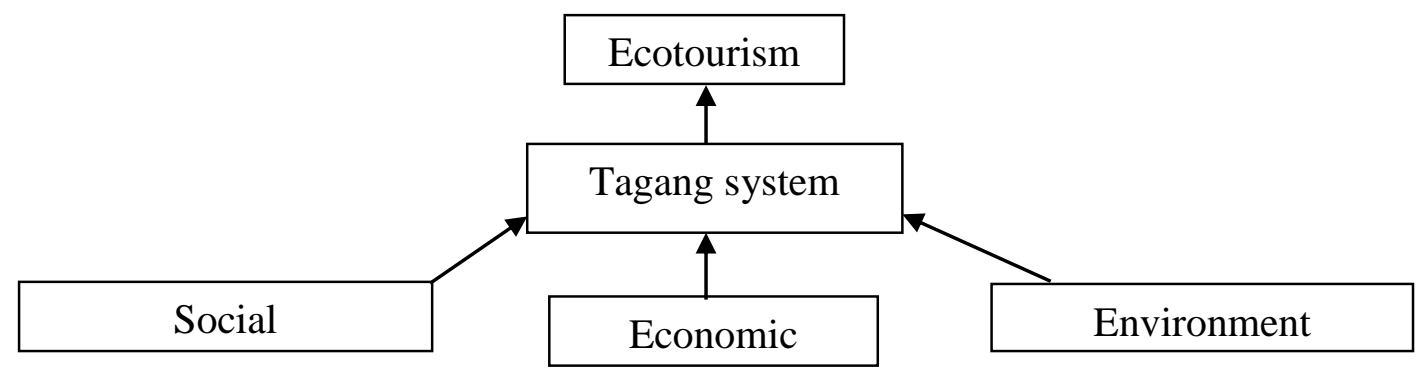

Figure 1: Conceptual framework of Tagang system in Semedang village

Source: Foo (2011).

\section{Data Collection}

The population of this study consists of the local communities that live at Semedang area and tourists, whether internal or external tourists which visit the village. This research used probability sampling in the study. For this research, the structured formulated by Crang \& Cook (2007) is applied. Interview schedule akin to the questionnaire and the semi-structured are relatively unstructured interviews is applied to the head of the village, head of the Tagang system, local communities and visitors. The purpose of these interviews is to gain a better understanding of the development of a Tagang system in the ecotourism framework at Semedang village in depth and more details.

There are 70 sets of questionnaires that are distributed. The survey is divided into two sections whereby Section $A$ is about the demographic profile (example gender, age, educational level, income level) of the respondent and Section B consisted of questions that used to investigate the significant impacts of Tagang system in term of ecotourism at Semedang village. Items in Section B are measured using the Likert Scales with values of 1 indicating strongly disagree, 2 indicates disagree, 3 indicates neutral, 4 indicates agree and 5 indicates strongly agree.

\section{Methodology}

70 questionnaires were distributed randomly to the stakeholder of Tagang systems and only 63 are returned. Statistical package for the social sciences (SPSS) is used to analyse the data collected. Likert scale was applied in this research as a measure of scales in the survey. Factor analysis using Principal component analysis (PCA) was conducted as the variable reduction method by reducing the data into the sample set of variable (Dunteman, 1989). PCA was implemented by taking into account a particular variable that considers the extraction of the components. The factor analysis contains preliminary analysis, factor rotation and factor extraction. The factor analysis for the initial study entails the Kaiser-Meyer-Olkin (KMO) statistic that is employed to study the diagonal elements of the anti-image correlation matrix. The process of factor extraction was conducted by calculating the eigenvalues of the R-matrix to examine the linear component contained by the eigenvectors. The factor analysis would distinguish the significance of a certain vector to identify the degree associated with eigenvalue and regulate which factors or components to maintain or remove. The eigenvalues larger than 1 is a standard for retaining factors based on the Kaiser's criterion. Later, factor rotation was applied by using orthogonal rotation (varimax) in order to maximise the 
dispersion of loadings within factors to obtain the structure of factor. Then, the reliability test was conducted to assess the consistency. Cronbach's alpha, $\alpha$, shows the overall reliability of a survey and values about 0.80 are considered good and to examine whether the selected model will be retained or discarded. The method was used to ensure certain items/questions in the survey are grouped based on the appropriate factors which contributed to Tagang system development in Semedang village.

\section{RESULTS AND DISCUSSIONS}

\section{Respondents' Demographic Profiles}

Based on Table 1, from the total number of 63 respondents, $52.4 \%$ of them are male, and $47.6 \%$ of them are females. The majority of the respondents is in the age group of 31 to 40 (28.6\%), followed by the age group of fewer than 21 years old (23.8\%), the age group 21 to $30(19.0 \%)$, the age group of 41 to 50 and more than 60 years old $(11.1 \%)$, and there is only $6.3 \%$ is coming from the age group of 51 to 60 years old.

Regarding race and religion, 100 per cent of the respondents is Bidayuh and Christian. On the education level, most of the respondents are still in secondary school, which is $66.7 \% .11 .1$ $\%$ of the respondents are at the level of primary school and had completed their Diploma, and $7.9 \%$ of the respondents are not listed in education level or did not have any education from primary to PhD. There is only $1.6 \%$ of respondents who at the level of Master and PhD.

The majority of the respondents' income level is lower than RM 1000 which is $66.7 \%$, followed by the respondents who are at an income level in between RM 1001 to RM 2000 (14.3\%), $11.1 \%$ of them are at an income level in between RM 2001 to RM 3000, 3.2 \% of them are from the income level of RM 3001 to RM5000, and only $1.6 \%$ of the respondents are gaining an income level of more than RM 5000. 
INTERNATIONAL JOURNAL OF ACADEMIC RESEARCH IN BUSINESS AND SOCIAL SCIENCES Vol. 8, No. 11, Nov, 2018, E-ISSN: 2222-6990 @ 2018 HRMARS

Table 1: Respondents' demographic profile $(n=63)$

\begin{tabular}{|c|c|c|c|}
\hline \multicolumn{2}{|c|}{ Demographic variables } & \multirow{2}{*}{$\begin{array}{c}\text { Frequency } \\
33\end{array}$} & \multirow{2}{*}{$\begin{array}{c}\text { Percent } \\
52.4\end{array}$} \\
\hline Gender & Male & & \\
\hline & Female & 30 & 47.6 \\
\hline \multirow[t]{6}{*}{ Age } & $\leq 20$ & 15 & 23.8 \\
\hline & $21-30$ & 12 & 19.0 \\
\hline & $31-40$ & 18 & 28.6 \\
\hline & $41-50$ & 7 & 11.1 \\
\hline & $51-60$ & 4 & 6.3 \\
\hline & $\geq 61$ & 7 & 11.1 \\
\hline \multirow[t]{7}{*}{ Employment } & Government & 10 & 15.9 \\
\hline & Private & 17 & 27.0 \\
\hline & Retired & 4 & 6.3 \\
\hline & Student & 15 & 23.8 \\
\hline & Unemployment & 1 & 1.6 \\
\hline & Business & 2 & 3.2 \\
\hline & Other & 14 & 22.2 \\
\hline \multirow[t]{6}{*}{ Education } & None & 1 & 1.6 \\
\hline & Primary & 7 & 11.1 \\
\hline & Secondary & 42 & 66.7 \\
\hline & Diploma & 7 & 11.1 \\
\hline & Master/PhD & 1 & 1.6 \\
\hline & Other & 5 & 7.9 \\
\hline \multirow[t]{3}{*}{ Household } & $\leq 5$ & 26 & 41.3 \\
\hline & $6-11$ & 35 & 55.6 \\
\hline & $\geq 12$ & 2 & 3.2 \\
\hline \multirow[t]{6}{*}{ Income } & $\leq 1000$ & 42 & 66.7 \\
\hline & $1001-2000$ & 9 & 14.3 \\
\hline & $2001-3000$ & 7 & 11.1 \\
\hline & $3001-4000$ & 2 & 3.2 \\
\hline & $4001-5000$ & 2 & 3.2 \\
\hline & $\geq 5001$ & 1 & 1.6 \\
\hline
\end{tabular}

Based on Table 2, the value of the sampling adequacy Kaiser-Meyer-Olkin (KMO) in this study was equal to 0.759 , which indicated that the analysis is "average". It shows a better reflection of the performance on the variables in this study and the value demonstrates the acceptable internal consistency of the components. Barlett's test with a significance level of acceptability $(p<0.001)$ components proved to be suitable for performing the factor analysis, and it cannot be rejected whereby the Chi-Square equal to 728.518 .

Table 2: KMO and Bartlett's Test

\begin{tabular}{lll}
\hline Kaiser-Meyer-Olkin Measure of Sampling Adequacy & 0.759 \\
\hline Bartlett's Test of Sphericity & Approx. Chi-Square & 728.518 \\
\cline { 2 - 3 } & df & 210 \\
\cline { 2 - 3 } & Sig. & .000 \\
\hline
\end{tabular}

Table 3 shows that the Cronbach's Alpha was 0.830 for the whole questions with a Likert Scale of 21 items. This demonstrates that the reliability of the questionnaires was high with value approaches a value of 1 , indicating that the data is acceptable. 
Table 3: Reliability test of 21 variables

\begin{tabular}{cc}
\hline Cronbach's Alpha & Number of items (N) \\
\hline 0.830 & 21 \\
\hline
\end{tabular}

Based on Table 4, six components are extracted which have an eigenvalue higher than 1. All the remaining factors are not significant. This is supported by the scree plot (Figure 2 ) which has a point of inflection after six factors.

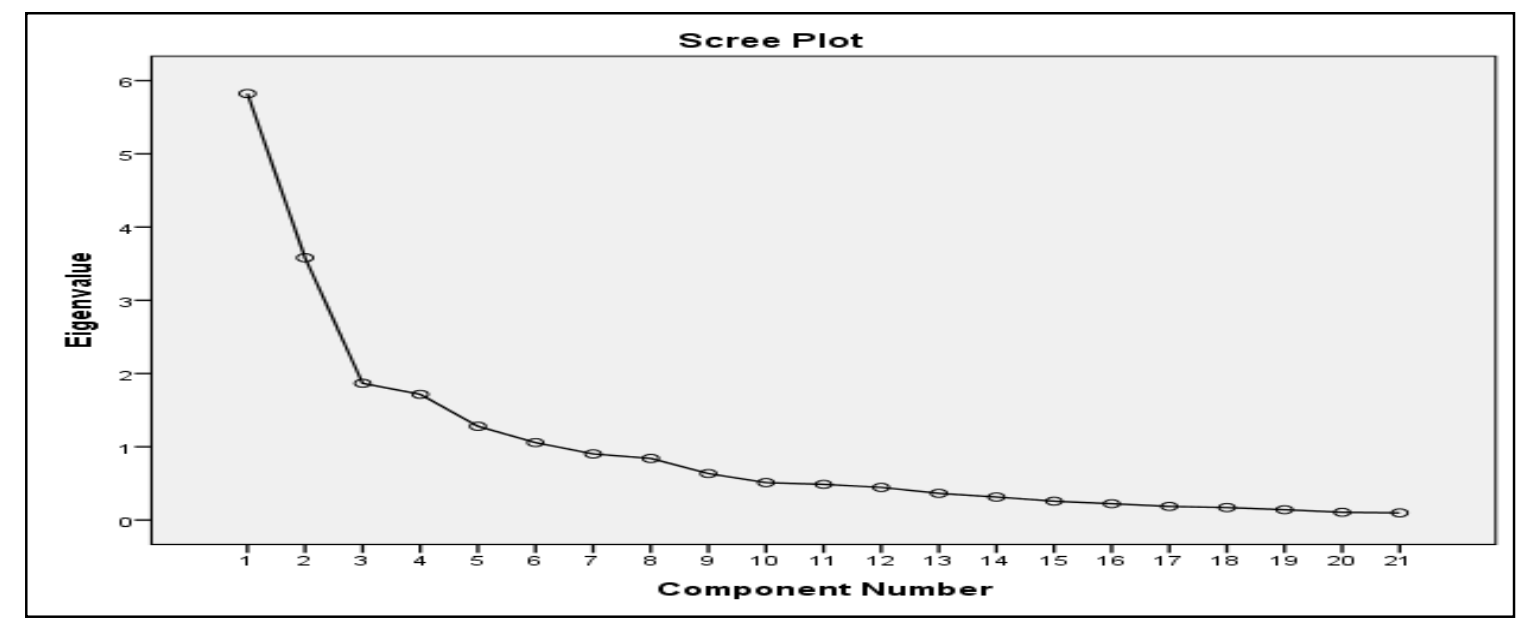

Figure 2: Scree plot

Table 5 shows the Rotated Component Matrix which is a matrix of the factor loadings for each variable into each component. There are six questions that load highly on component 1 and labelled as Economic Development, four items highly loaded on component 2 and labelled as Conservation of Natural Area, three questions highly loaded on component 3, labelled as Awareness of Tagang Advantages, two questions each highly loaded on component 4 and 5 which are labelled each as Biodiversity Management for component 4 and Environment and Society for component 5. Lastly, only one question highly loaded on component 6 and labelled as Cultural.

According to Cooper \& Schindler (2006), it is stated that the Eigenvalue can be defined as the proportions of all the variables explained by factors. In addition, the Eigenvalue is the total variance explained by more than one variable. Henry Kaiser in an article by Darlington (1997) stated that only the Eigenvalue with a value greater than 1 could be considered as necessary for the analysis. 
INTERNATIONAL JOURNAL OF ACADEMIC RESEARCH IN BUSINESS AND SOCIAL SCIENCES Vol. 8, No. 11, Nov, 2018, E-ISSN: 2222-6990 @ 2018 HRMARS

Table 4: Total Variance Explained

\begin{tabular}{|c|c|c|c|c|c|c|c|c|c|}
\hline \multirow[b]{2}{*}{$\begin{array}{l}\text { Compone } \\
\mathrm{nt}\end{array}$} & \multicolumn{3}{|c|}{ Initial Eigenvalues } & \multicolumn{3}{|c|}{ Extraction Sums of Squared Loadings } & \multicolumn{3}{|c|}{ Rotation Sums of Squared Loadings } \\
\hline & Total & $\begin{array}{c}\% \text { of } \\
\text { Variance }\end{array}$ & $\begin{array}{c}\text { Cumulative } \\
\%\end{array}$ & Total & $\begin{array}{c}\% \text { of } \\
\text { Variance }\end{array}$ & $\begin{array}{c}\text { Cumulative } \\
\%\end{array}$ & Total & $\begin{array}{c}\% \text { of } \\
\text { Variance }\end{array}$ & $\begin{array}{c}\text { Cumulative } \\
\%\end{array}$ \\
\hline 1 & 5.823 & 27.727 & 27.727 & 5.823 & 27.727 & 27.727 & 4.638 & 22.084 & 22.084 \\
\hline 2 & 3.581 & 17.051 & 44.777 & 3.581 & 17.051 & 44.777 & 3.353 & 15.966 & 38.049 \\
\hline 3 & 1.867 & 8.890 & 53.667 & 1.867 & 8.890 & 53.667 & 2.539 & 12.092 & 50.142 \\
\hline 4 & 1.716 & 8.173 & 61.840 & 1.716 & 8.173 & 61.840 & 1.979 & 9.423 & 59.565 \\
\hline 5 & 1.279 & 6.093 & 67.933 & 1.279 & 6.093 & 67.933 & 1.658 & 7.894 & 67.459 \\
\hline 6 & 1.057 & 5.033 & 72.966 & 1.057 & 5.033 & 72.966 & 1.157 & 5.507 & 72.966 \\
\hline 7 & .902 & 4.297 & 77.263 & & & & & & \\
\hline 8 & .841 & 4.005 & 81.267 & & & & & & \\
\hline 9 & .634 & 3.020 & 84.287 & & & & & & \\
\hline 10 & .511 & 2.432 & 86.719 & & & & & & \\
\hline 11 & .487 & 2.318 & 89.037 & & & & & & \\
\hline 12 & .445 & 2.118 & 91.155 & & & & & & \\
\hline 13 & .364 & 1.735 & 92.890 & & & & & & \\
\hline 14 & .314 & 1.494 & 94.384 & & & & & & \\
\hline 15 & .257 & 1.225 & 95.609 & & & & & & \\
\hline 16 & .222 & 1.058 & 96.667 & & & & & & \\
\hline 17 & .186 & .884 & 97.551 & & & & & & \\
\hline 18 & .170 & .810 & 98.361 & & & & & & \\
\hline 19 & .141 & .671 & 99.032 & & & & & & \\
\hline 20 & .105 & .502 & 99.534 & & & & & & \\
\hline 21 & .098 & .466 & 100.000 & & & & & & \\
\hline
\end{tabular}

Extraction Method: Principal Component Analysis. 
INTERNATIONAL JOURNAL OF ACADEMIC RESEARCH IN BUSINESS AND SOCIAL SCIENCES

Vol. 8, No. 11, Nov, 2018, E-ISSN: 2222-6990 @ 2018 HRMARS

Table 5: Rotated Component Matrix

\begin{tabular}{|c|c|c|c|c|c|c|}
\hline \multirow[t]{2}{*}{ Variables } & \multicolumn{6}{|c|}{ Components } \\
\hline & 1 & 2 & 3 & 4 & 5 & 6 \\
\hline Generates employment & 0.885 & & & & & \\
\hline Improves economic well-being & 0.863 & & & & & \\
\hline Increase the tourists & 0.803 & & & & & \\
\hline Develop tourism sector & 0.793 & & & & & \\
\hline Increase the income & 0.793 & & & & & \\
\hline Increase the living standard & 0.620 & & & & & \\
\hline Disruption in fishbreeding & & 0.879 & & & & \\
\hline Disruption in Tagang zones & & 0.868 & & & & \\
\hline Illegal fishing & & 0.77 & & & & \\
\hline Crime rate and security issues & & 0.655 & & & & \\
\hline $\begin{array}{l}\text { Provide more advantages in the } \\
\text { society }\end{array}$ & & & 0.735 & & & \\
\hline $\begin{array}{l}\text { Provide more advantages in the } \\
\text { economic }\end{array}$ & & & 0.727 & & & \\
\hline $\begin{array}{l}\text { Provide more advantages in the } \\
\text { environmental }\end{array}$ & & & 0.697 & & & \\
\hline $\begin{array}{l}\text { Protection of the riverine system and } \\
\text { its ecology }\end{array}$ & & & & 0.857 & & \\
\hline River and its fishes to be manageable & & & & 0.662 & & \\
\hline Increases the variety of fish species & & & & & 0.812 & \\
\hline $\begin{array}{l}\text { Communicate with international } \\
\text { tourists }\end{array}$ & & & & & 0.728 & \\
\hline $\begin{array}{l}\text { Culture and heritage of local } \\
\text { communities }\end{array}$ & & & & & & 0.816 \\
\hline Eigenvalue & 5.823 & 3.581 & 1.867 & 1.716 & 1.279 & 1.057 \\
\hline$\%$ of variance & 22.084 & 15.966 & 12.092 & 9.423 & 7.894 & 5.507 \\
\hline Cumulative $\%$ of variance & 22.084 & 38.049 & 50.142 & 59.565 & 67.459 & 72.966 \\
\hline Reliability & 0.905 & 0.819 & 0.821 & 0.710 & 0.511 & - \\
\hline $\begin{array}{l}\text { Number of items } \\
(\mathrm{N}=21)\end{array}$ & 6 & 4 & 3 & 2 & 2 & 1 \\
\hline
\end{tabular}

Thus, the first component of Economic development, the Eigenvalue was 5.823 with the percentage of variance was 22.084, the cumulative percentage of variance of these components is 22.084 , and the reliability is 0.905 . Refer to table above, found that by six variables that can be used in component 1 (Economic development) from 0.620 to 0.885 consisting of "Ecotourism generates greater employment opportunities" (0.885), "Ecotourism improves the economic well-being of the local communities" (0.863), "Ecotourism activities increase in the number of tourists" (0.803), "Tagang system increases the development of tourism sector in Sarawak" (0.793), "Ecotourism activities increase the income of local communities" (0.793), and "Ecotourism can increase the standard of 
living of the local community" (0.620). This shows that the communities perceived the ecotourism activities are deemed as necessary in generating economic activities. Thus, to improve the livelihood of the communities, events such as kayaking, water rafting and fish feeding are considered as among the popular ecotourism activities that could contribute to the success of ecotourism in Tagang system locations.

The second component of Conservation of natural area consisting of four components with values ranging from 0.655 to 0.879 . The components present in this factor is "Ecotourism activities cause disruptions in fish breeding" (0.879), "Ecotourism activities cause disruptions in Tagang zones" (0.868), "Ecotourism can lead to illegal fishing" (0.77), and "Ecotourism can increase crime rates and security issues" (0.655). This situation indicates that all components of this factor explain the factors with the best way to (>0.6). Based on these components, the Eigenvalue is 3.581 with the percentage of variance is 15.966 and the cumulative percentage is 38.049 with the reliability of this component is 0.819 and approaching 1 where it can be trusted. Tagang activities are restricted in 3 zones namely the green zone, yellow zone and red zone (Wong et al., 2009). The green zone is known as the "open fishing zone" in which fishing activities are approved all year around under strict Tagal (Tagang) regulations using lawful fishing methods. The yellow zone, on the other hand, opens once or twice a year specifically during community celebrations or celebrations. Finally, the red zone is prepared entirely for conservation of the communities' fish stocks. This zone is also made for ecotourism in which visitors can enter and enjoy the activities such as sports (water rafting, kayaking), bathing, and playing with the fish (fish feeding and fish massage) at a certain amount of fees. Communities expressed their concern on the impact of ecotourism towards the sustainability of Tagang system in the long run, particularly in sustaining the fish stocks and the protection of the riverine system from any threats.

For the third component which is Awareness of Tagang advantages factor have three components with values ranging from 0.655 to 0.735 . All components showed the Eigenvalue is 1.867 , the percentage of variance is 12.092 , while the value of the cumulative percentage of variance is 50.142 and the reliability is approaching 1 in which case it is 0.821 . Based on the results of the study found that these components have variable levels of good (>0.6) consists of components that "Overall, the ecotourism activities provide more advantages than disadvantages in the social perspective" (0.735), "Overall, ecotourism activities provide more advantages than disadvantages in the economic perspective" (0.727), and "Overall, ecotourism activities provide more advantages than disadvantages in the environmental perspective" (0.697). The results support the communities' awareness of the advantages gained from the socio-economic and the environmental perspective. The communities believe that the Tagang system if properly managed could contribute towards the tourism sector in the long-run.

A fourth component is a factor in Biodiversity management consists of two components with the values ranging from 0.662 to 0.857 . Overall two components show the Eigenvalue of 1.716 , the percentage of variance is 9.423 and the cumulative percentage of variance is 59.565 of which reliability is $\mathbf{0 . 7 1 0}$. This component consists of only two components and the total value of the variables describing it is good. Among them is a component of "Ecotourism increases the protection 
of the riverine system and its ecology" $(0.857)$, and "Ecotourism activities cause the river and its fishes to be more manageable" (0.662). The communities are very concerned with the environment, particularly in protecting the river ecology and the manageability of the fish species. Furthermore, by maintaining the riverine, it is most likely to sustain and support Tagang system in a more extended period.

Next, the fifth component is a factor of Environment and society where the Eigenvalue is 1.279 , the percentage of variance is 7.894, and the cumulative percentage of variance is 67.459 with the reliability of this component is 0.511 . There are only two variables in this vector component comprising "Ecotourism increases the variety of fish species", and "It is burdensome for local communities to communicate with the international tourists", with values ranging from 0.728 to 0.812. However, since the Cronbach's Alpha of Environment and society factor is below than 0.6, it is not an acceptable benchmark, then this variable cannot be a factor that given impacts to the Tagang system and should be deleted.

The last components of Cultural factors ranging from one component variable of "Tourists are attracted to the culture and heritage of local community" (0.816), noting the Eigenvalue of 1.057, 5.507 the percentage of variance and cumulative percentages of variance is 72.966 . However, the value of reliability for this factor is unknown since the components cannot be analysed. This indicates that these variations should be deleted and showed very weak reliability.

From the results, there are only four factors that achieve an acceptable benchmark and relatively have a strong relationship with the Tagang system in the ecotourism framework with the value of Cronbach's Alpha ranging from 0.710 to 0.905 including Biodiversity management, Conservation of natural area, Awareness of Tagang advantages, and Economic development.

\section{CONCLUSION}

This study has attempted to determine the underlying variables of the perceived impacts of Tagang system development in ecotourism framework that is implemented in the Semedang village by local communities. The factor analysis yielded four factors which are Economic Development, Conservation of Natural Areas, Awareness of Tagang Advantage, and Biodiversity Management, with each factor having a satisfactory level of reliability (Cronbach's Alpha). There is a gap between the levels of stakeholders. Despite showing their support on the ecotourism and the Tagang system, it is noted that some of the villagers are not fully aware with how the system functions and how they can contribute to the longevity of the system and the fishes. The villagers also experience some difficulties in maintaining the cleanliness of the river, given the pollution caused upstream which could pose a threat to the survival of the fishes. In the long-run, the villagers are planning to expand the ecotourism activities in Semedang River by encouraging better tourism activities. This is by promoting existing and more tourism products and attractions such as caves, homestays and cultural based events. 
Tagang system in Sarawak is still at its infant stage. It is noted that substantial and consistent efforts and cooperation from all stakeholders are deemed crucial to achieve long-term sustainability. Greater initiatives from all level including the communities, tourists, tour operators, environmental institution and government could contribute to the development of Tagang system as well as in improving in the communities' quality of life. Suggestions for future research would be most likely to include more villages in Sarawak as well as applying the regression method and structural equation modelling for more in-depth analysis.

\section{ACKNOWLEDGEMENT}

The authors acknowledge the financial support from Universiti Malaysia Sarawak (UNIMAS) and Research Acculturation Grant Scheme [RAGS / e (9) / 908/ 2012(09)]. All remaining flaws are the responsibilities of the authors.

\section{REFERENCES}

Cooper, C., \& Wanhill, S. (1996). Tourism. London: Pitman.

Cooper, D. R., \& Schindler, P. S. (2006). siness research methods. New York: McGraw-Hill Companies Inc.

Crang, M., \& Cook, I. (1995). Doing Ethnographies. Norwich: Geobooks. https://doi.org/10.4135/9781849208949

Darlington, R. B. (1997). Factor analysis. New York. Retrieved from http://node101.psych.cornell.edu/Darlington/factor.htm

Dunteman, H. G. (1989). Principal Components Analysis. SAGE Publications.

Err, A. C., Selvadurai, S., Lyndon, N., Chong, S. T., Adam, J. H., Mohd Fuad, M. J. ., ... Hamzah, J. (2012). The Evolvement of Tagal on Ecotourism and Environmental Conservation: A Case Study in Kampong Luanti Baru, Sabah. Advances in Natural and Applied Sciences, 6(1), 61-64.

Foo, J. M. (2011). Sistem tagal dalam industri pelancongan: Manfaat kepada komuniti. Geografia Malaysian Journal of Society and Space , 7(1), 14-25. https://doi.org/10.1155/2009/406965

Wearing, S., \& Neil, J. (1999). Ecotourism: Impacts, Potentials and Possibilities. London: Reed Educational and Professional Publishing Ltd.

Wong, J. Z., Etoh, S., \& Sujang, A. B. (2009). Towards Sustainable Community-based Fishery Resources Management: The Tagal System of Sabah, Malaysia. Fish for the People, 7(2), 18-23. Retrieved from http://mahseertrust.org/wp-content/uploads/2016/05/Wong-2009.pdf 